\title{
CYBERSECURITY IN PANDEMIC TIMES: CHALLENGES AND OPPORTUNITIES
}

\author{
Ana Ferreira ${ }^{1,2}$ and Ricardo Cruz-Correia ${ }^{1,2}$ \\ ${ }^{1}$ CINTESIS - Center for Health Technology and Services Research \\ ${ }^{2}$ Departamento Medicina da Comunidade, Informação e Decisão em Saúde (MEDCIDS) \\ Faculty of Medicine, University of Porto, Portugal
}

\begin{abstract}
In times of COVID-19 and isolation, many are the challenges related to a proper balance between patient's personal and sensitive data privacy and protection, and the need to use those data to better understand the disease and act in a more efficient and quick manner, to fight it. Some research is available on how to tackle a few of these issues in isolation, however, there is a need for a more comprehensive overview of what are the current security challenges, what is being done to face them, and what still needs addressing. Since the control of this pandemic depends on the actions of every individual, when there is no trust in the technology or services provided, allied to the fear and uncertainty of the current context, it is very difficult to provide an integrated and informed response to this disease. The main goal of this paper is to expose and address vulnerabilities and risks associated to patients' data protection and COVID-19. Thirty-two direct, and 25 indirect consequences of COVID-19 to data privacy and cybersecurity, were identified. There is the need for more comprehensive and resilient solutions addressed by the research community, from multidisciplinary sources of knowledge.
\end{abstract}

\section{KEYWORDS}

Cybersecurity, Privacy, COVID-19, Health Data Protection, Quarantine and Isolation

\section{INTRODUCTION}

When we think about COVID-19 and the current pandemic, the last thing that comes into our mind is the subject of cybersecurity. Yet, more than ever, cybersecurity is crucial for all that is connected with COVID-19, both directly, in terms of research and active treatment and containment, and indirectly, with all the side effects and consequences that it has created. One of the most direct consequences of COVID-19 in cybersecurity relates with the use and sharing of personal and health data from patients that contracted the new coronavirus. It is suggested that the more such analyses are initiated and concluded openly, in accordance with the law and with due respect for privacy and confidentiality, the greater will be the public trust and the ability to produce reliable analytic insights (Jawaid, 2020)(Ienca, 2020). Failing to do so will undermine public trust and adherence to public-health recommendations, which can result in poorer health outcomes (Ienca, 2020). Moreover, extensive gathering of diagnostic data on who is infectious may be essential to save lives, train Artificial Intelligence systems, and limit economic damages (Naudé, 2020).

Still related to this issue are patients' data shared in the context of contact tracing. Contact tracing using smartphone technology is a powerful tool that may be employed to limit disease transmission during a pandemic, enforce quarantine rules, notify risk zones or warn infected people (Abeler, 2020). However, contact tracing apps present significant privacy concerns since they collect personal data, such as location (Yasaka, 2020), which can be used to perform a high degree of surveillance and harm to the human right to privacy. There have been some works that try to find the right balance between the required data and user's privacy, by not collecting location data, but only using anonymized graph of interpersonal interactions, stored locally on the smartphone device (Yasaka, 2020).

More indirect consequences of the current pandemic to data privacy and security are associated to the current isolation of people, who are confined to their homes or a single physical location, for long periods of time. A high percentage of the humanity is isolated or in lockdown and rely on digital infrastructures to perform most of their daily activities. Working from home, home-schooling, online shopping, home-banking, contact 
with friends and family, and even exercising and entertaining activities, are all being performed using the Internet 24/7. There are many implications on cybersecurity and physical security that arise from this situation such as the need to deal with most pressing issues related to diseases, other than COVID-19. Healthcare professionals have to opt for other means to support their patients such as: tele-consultation, advice via email, whatsapp, or similar platforms (Rajkumar, 2020)(Kavoor, 2020)(Now, 2020). Moreover, digital home equipment, as well as their users, are most probably not prepared to securely provide this type of interaction. On the other hand, the confinement situation can also exacerbate the need for this type of support from vulnerable populations, such as chronic, oncological, and mental health patients (Jawaid, 2020)(Yao, 2020)(Rajkumar, 2020), where the usual assistance in an hospital or other healthcare institutions is not advised during this period, not only for the high risk of becoming infected with COVID-19 (more dangerous on patients with comorbidities) but also, due to the lack of healthcare resources available.

The provided examples are just a small set which clearly motivates and justifies this research work. The aims of this paper are to: 1) identify the main vulnerabilities and risks associated, both directly and indirectly, to healthcare data protection and COVID-19; 2) understand how the research community is tackling these cybersecurity challenges; 3 ) expose the identified gaps that still need addressing by that community; and 4) further discuss the identified challenges to press the advancement of existing knowledge, to achieve a better balance between patient's privacy and their data use, to effectively fight this pandemic.

\section{METHODS}

A literature review of the research performed in this area was performed. Inclusion criteria comprised works in English, published from January to May 2020, which link the pandemic with privacy/security issues (e.g., "security OR privacy OR confidentiality" AND "covid OR pandemic"). Searches were performed in 5 database engines and works were reviewed by their titles and abstracts first, with repeated works excluded (Figure 3). The selected works were analysed by: Type of work (article, letter, comment, etc); Database engine; Direct/Indirect consequence from COVID-19; Main subject; Goal(s); Problem raised; and Proposed solution, and they were divided in two categories:

- Directly related to the combat of the disease (Figure 1), i.e., i) the need to use patient's personal and sensitive data for analysis, control of the disease propagation and transmission; ii) the exposure of the lack of investment in critical security infrastructures; and iii) the increase of fraud and theft via email, SMS or social networks;

- Indirectly related to the combat of the disease (Figure 2), i.e., i) associated to consequences of the pandemic, mostly related to the isolation and confinement situation and their influence to other non-covid-19 related diseases, such as mental health, chronic diseases or other health conditions that need remote managing (teleconsultation, online advice; dealing with health emergencies); and ii) augmented risks to physical security, with stress on constantly using home/personal digital infrastructures and devices, for other contexts and goals, for which they are not security prepared.

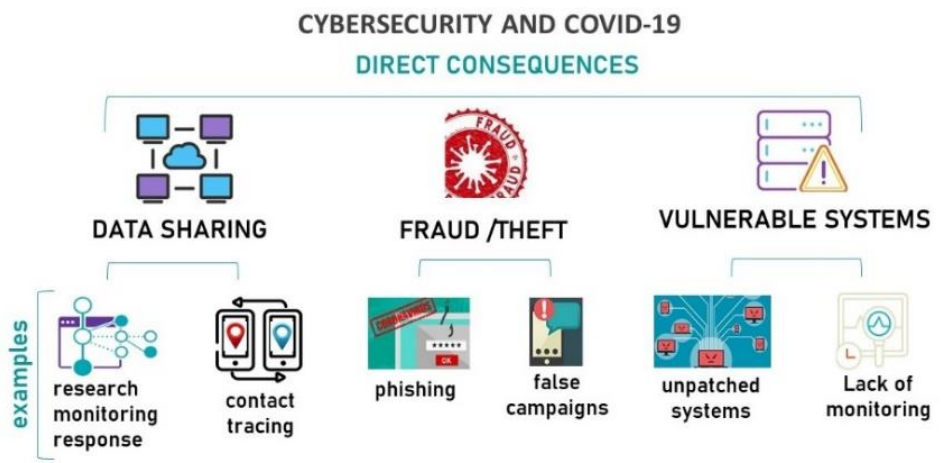

Figure 1. Cybersecurity challenges/consequences DIRECTLY related to COVID-19 


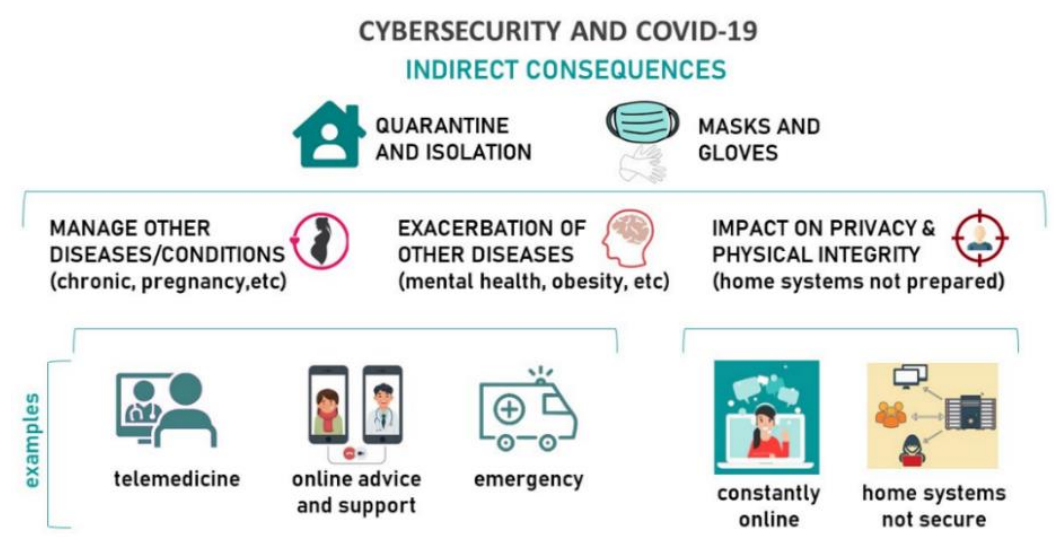

Figure 2. Cybersecurity challenges/consequences INDIRECTLY related to COVID-19

1.

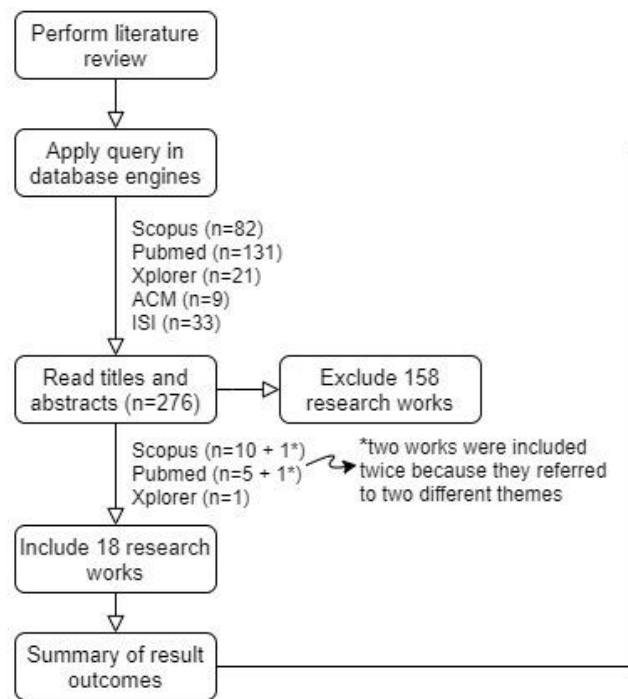

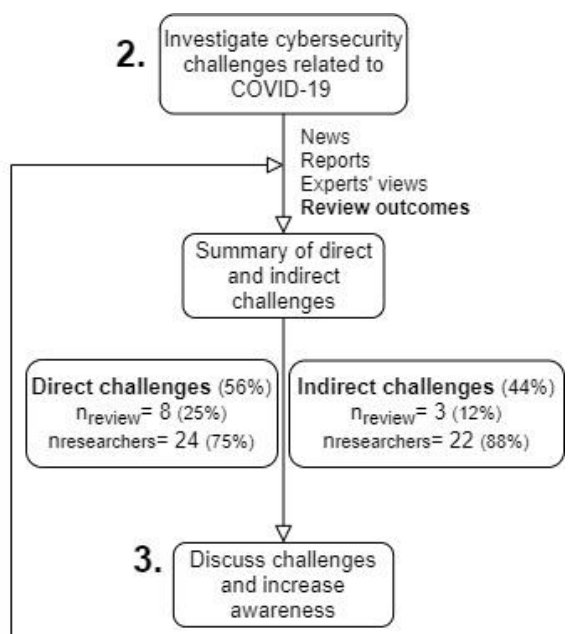

Figure 3. Illustration of the methods performed in this work

\section{RESPONSE FROM THE RESEARCH COMMUNITY}

Eighteen research works (10 articles; 8 comment/letters/opinions) were included in the review. These focus mostly on sharing data to find out more about the disease (8), provide means to trace infected people (7), better understand how the disease propagates and the implications in terms of privacy and data protection. In terms of consequences of COVID-19 to cybersecurity, $83 \%(n=15)$ of the works focus on direct (i.e., data sharing and contact tracing), while $17 \%(\mathrm{n}=3)$, on indirect consequences (i.e., mental health (2) and legal procedures (1)). Common problems and proposed solutions are highlighted in Tables 1 and 2, respectively.

Table 1. Cybersecurity problems and concerns found in the review, directly or indirectly associated with COVID-19

\begin{tabular}{llll}
\hline Areas of research & Cybersecurity problems/concerns found in the review & References \\
\hline DATA SHARING* & & (Pesce) \\
\cline { 2 - 4 } & Breach of privacy can result in decreased compliance, public trust and adherence & (Nature) \\
Contact Tracing & (Ienca) & (Pesce) \\
& & How to wind back to a world with greater privacies after the crisis abates? & (Kummitha) \\
\cline { 2 - 4 } & Countries are developing apps independently, and there are no global standards & (Nature)
\end{tabular}


Scant evidence on how effective these apps are/will be

Contact data such as location in tracing apps present significant privacy concerns

It is becoming easier to identify individuals from anonymized data sets

Virologists/epidemiologists are consulted, and other health/non-health experts?

Other purposes

Health professionals should share their knowledge/suspicion a patient is infected to others when 'distancing'/'shielding' is impracticable, ineffective or refused
(Nature)

(Yasaka)

(Finch)

(Nature)

(Rajan)

(Finch)

\begin{tabular}{rllll}
\hline MANAGE OTHER DISEASES REMOTELY & & \\
Mental health & $\begin{array}{l}\text { Social isolation in seniors has been linked to increased depression, suicidality, } \\
\text { proinflammatory and decreased immune responses - privacy and safety concerns }\end{array}$ & (Jawaid) \\
\cline { 2 - 3 } Impact on diseases & $\begin{array}{l}\text { Epidemics do not affect all population equally, which can contribute to the } \\
\text { spreading of infections - privacy and safety concerns }\end{array}$ & (Yao) \\
Legal procedures & Laws to arrest people infected to limit the spread of disease - privacy concerns & (Finch) \\
\hline \hline
\end{tabular}

"DIRECT CONSEQUENCES; ${ }^{+}$INDIRECT CONSEQUENCES

Table 2. Cybersecurity solutions found in the review, directly or indirectly associated with COVID-19

\begin{tabular}{|c|c|c|}
\hline Areas of research & Cybersecurity solutions found in the review & References \\
\hline \multicolumn{3}{|l|}{ DATA SHARING* } \\
\hline \multirow{6}{*}{ Contact Tracing } & Use anonymized graph of interactions to conduct contact tracing apps & (Yasaka) \\
\hline & Apps should not be rolled out without pilot studies or risk assessments & (Nature) \\
\hline & Apps that link to official validated tests are more likely to give accurate results & (Nature) \\
\hline & The need for data minimisation for tracing apps & (Mirco) \\
\hline & Critical to balance the need for information with legitimate privacy concerns & $($ Park)(Abeler) \\
\hline & Contact tracing is possible without collecting a lot of data in central databases & (Abeler) \\
\hline \multirow{8}{*}{ Other purposes } & $\begin{array}{l}\text { Provide insights to guide behaviour of individuals, public policy and dialogue - } \\
\text { provide transparency on how, when, and why data are being used }\end{array}$ & $\begin{array}{c}\text { (Pesce) } \\
\text { (Rajan) } \\
\text { (Mirco) } \\
\text { (Jawaid) } \\
\text { (Kummitha) }\end{array}$ \\
\hline & $\begin{array}{l}\text { More involvement from researchers, also from ethics and law, and commitment } \\
\text { from governments that personal data is secure and used only for requested reasons }\end{array}$ & (Nature) \\
\hline & $\begin{array}{l}\text { Create a unified framework for data exchange about the epidemic and research is } \\
\text { an essential step towards effective responses to the challenges we currently face }\end{array}$ & (Lenert) \\
\hline & $\begin{array}{l}\text { Use these data and algorithms in a responsible manner, in compliance with data- } \\
\text { protection regulations and due respect for privacy and confidentiality }\end{array}$ & $\begin{array}{l}\text { (Ienca) } \\
\text { (Jawaid) }\end{array}$ \\
\hline & Balance between data privacy, public health and rigorous human-AI interaction & (Naudé) \\
\hline & Build community-level resilience in order to cope with the crisis & \multirow{3}{*}{ y (Kummitha) } \\
\hline & Cities need to partner with each other and actively coordinate with governments & \\
\hline & $\begin{array}{l}\text { Need to share best practices among countries and encouraging different key } \\
\text { stakeholders to invent/implement technologies to detect/isolate infected patients }\end{array}$ & \\
\hline \multicolumn{3}{|c|}{ MANAGE OTHER DISEASES REMOTELY' ${ }^{+}$} \\
\hline Mental health & Keep elderly engaged/motivated with volunteers, hotlines or online resources & (Yao)(Jawaid) \\
\hline
\end{tabular}

\section{PANDEMIC CHALLENGES FOR CYBERSECURITY}

A brainstorm was performed by the authors, experts in cybersecurity, to identify complementary cybersecurity challenges associated with the COVID-19, not yet identified by the research community, DIRECTLY (Table 3 ) and INDIRECTLY (Table 4) related to COVID-19. 
Table 3. Privacy/security challenges DIRECTLY associated to COVID-19, not presented in Table 1

\begin{tabular}{|c|c|}
\hline Categories & Cybersecurity issues directly related to COVID-19 - NOT found in the review \\
\hline \multicolumn{2}{|l|}{ DATA SHARING } \\
\hline \multirow{9}{*}{ Contact Tracing } & EU member states need to comply with GDPR (e.g., right to be forgotten, access, etc) \\
\hline & Need for agreements from authorized Ethics Commissions (same for other purposes) \\
\hline & Lack of IT and cybersecurity literacy can compromise development/use of such apps \\
\hline & $\begin{array}{l}\text { Triangulation of tracing data, with data from the same device or service provider has } \\
\text { to be avoided. The device is not anonymous and other apps may share those data }\end{array}$ \\
\hline & Bluetooth has its known vulnerabilities depending on the device and protocol version \\
\hline & If these apps work, is there an effective return to the individual or the public health? \\
\hline & $\begin{array}{l}\text { Anonymized data: more susceptible to wardriving, jamming and sabotage, leading to } \\
\text { poor data quality, with no proper means available to guarantee data integrity }\end{array}$ \\
\hline & $\begin{array}{l}\text { Total anonymity is never possible because when people are in isolation, it can be easy } \\
\text { to find out who is infected or not, due to low interaction activities }\end{array}$ \\
\hline & Many false positives can be obtained when Bluetooth/GPS traverse walls, cars, etc \\
\hline \multirow{4}{*}{ Other purposes } & $\begin{array}{l}\text { Mandatory measure of body temperature or immunity tests of employees/students } \\
\text { before entering the premises. Need for proper national regulations for these issues }\end{array}$ \\
\hline & $\begin{array}{l}\text { Data sharing from government institutions for research purposes may be adequate and } \\
\text { justified. For example: GDPR has such provisions (Articles } 6(\mathrm{e}) \& 9(\mathrm{~g})(\mathrm{i}) \text { ) }\end{array}$ \\
\hline & $\begin{array}{l}\text { Feeding on the current fear of the population, authorities may act with impropriety to } \\
\text { the privacy of citizens without proper justification on why the decisions were made }\end{array}$ \\
\hline & $\begin{array}{l}\text { Integrity of research results needs to be checked by other impartial research groups to } \\
\text { make sure important decisions are taken based on the most current/correct data }\end{array}$ \\
\hline \multicolumn{2}{|l|}{ FRAUD \& THEFT } \\
\hline $\begin{array}{l}\text { Theft of health } \\
\text { emergency material }\end{array}$ & $\begin{array}{l}\text { International espionage and sabotage, like health material held or confiscated by } \\
\text { another country or region for which it was supposed to be delivered in the first place }\end{array}$ \\
\hline Ransomware & $\begin{array}{l}\text { Messages associated to COVID-19, with an increased degree of persuasion due to } \\
\text { fear and uncertainty, to block access to data and steal money by asking for a ransom }\end{array}$ \\
\hline Phishing & $\begin{array}{l}\text { Messages associated to COVID-19, with an increased degree of persuasion due to fear } \\
\text { and uncertainty, to steal credentials from online or banking accounts } \\
\text { Fake messages with online orders with an increased degree of persuasion since people } \\
\text { are in isolation and, therefore, buying many products online }\end{array}$ \\
\hline False campaigns & $\begin{array}{l}\text { False fundraising campaigns associated to COVID-19 with the false aim to help people } \\
\text { in distress or buy specific resources }\end{array}$ \\
\hline $\begin{array}{r}\text { Uncertified } \\
\text { material }\end{array}$ & $\begin{array}{l}\text { Non-certified or false health material that is sold (such ventilators, masks) which may } \\
\text { be very dangerous to whomever uses them (both patients and professionals) }\end{array}$ \\
\hline \multicolumn{2}{|c|}{ VULNERABLE SYSTEMS } \\
\hline Unpatched systems & Healthcare systems likely to be under budgeted and not with the latest patches/versions \\
\hline Lack of resources & Not enough technology/devices to monitor a high number of hospitalized patients \\
\hline Stress use & Health systems are diverse and not interoperable, which can make them less resilient \\
\hline Access control & $\begin{array}{l}\text { Lack of access control updating and monitoring may compromise patients' privacy, } \\
\text { with no control of the high turnover and additional professionals in times of pandemic }\end{array}$ \\
\hline $\begin{array}{r}\text { Vulnerable } \\
\text { communications }\end{array}$ & $\begin{array}{l}\text { Lack of systems protection can lead to more leakages in terms of communication via } \\
\text { many devices/technologies that can be used (smartphones, email, social networks, etc) }\end{array}$ \\
\hline
\end{tabular}

Table 4. Privacy/security challenges INDIRECTLY associated to COVID-19, not presented in Table 1

\begin{tabular}{|c|c|}
\hline Catgories & Cybersecurity issues indirectly related to COVID-19 - NOT found in the review \\
\hline \multicolumn{2}{|l|}{ MANAGE OTHER DISEASES } \\
\hline Telemedicine/online advice & Unsecure ho \\
\hline \multicolumn{2}{|c|}{ EXACERBATION OF CONDITIONS } \\
\hline Mental health, obesity, etc & Emergency/continued support v \\
\hline $\begin{array}{r}\text { Lack of timely resources - } \\
\text { medication/treatments }\end{array}$ & $\begin{array}{l}\text { Stress or lack of security in communication infrastructures can end in resources' } \\
\text { deviation or treatments' delay - privacy/physical security* }\end{array}$ \\
\hline
\end{tabular}




\begin{tabular}{|c|c|}
\hline \multicolumn{2}{|c|}{ PRIVACY \& PHYSICAL SECURITY* } \\
\hline \multicolumn{2}{|c|}{ Constantly online Increased } \\
\hline $\begin{array}{l}\text { Shared contexts (personal, } \\
\text { professional, familiar) }\end{array}$ & $\begin{array}{l}\text { The use of the same accounts on different devices, or different accounts on the same } \\
\text { device - prone to confusion and mistakes. No strong different passwords in them }\end{array}$ \\
\hline Unlocked sessions/devices & This situation, in shared spaces/contexts increases risk of attacks/mistakes \\
\hline Children and teenagers & $\begin{array}{l}\text { Increased time online in various activities (homeschooling, connect with friends, etc) } \\
\text { can increase risky behaviours and cyberbullying } \\
\text { Overburdened/distracted parents do not always monitor/control children's activities } \\
\text { There is a lack of IT and cybersecurity literacy from both parents and children }\end{array}$ \\
\hline Unsecure home channels & No custom use of secure communication channels, such as VPNs \\
\hline $\begin{array}{r}\text { Equipment } \\
\text { configurations/patches }\end{array}$ & $\begin{array}{l}\text { Not updated anti-virus or anti-malware software, lack of timely patching, no } \\
\text { passwords, weak passwords or same passwords, for different equipment/devices }\end{array}$ \\
\hline Regular Video calls & $\begin{array}{l}\text { Privacy threats with the use of personal spaces, images of children or other personal } \\
\text { information in the background }\end{array}$ \\
\hline Shared spaces & $\begin{array}{l}\text { Increased frequency, due to quarantine, of discussing/disclosing personal, private or } \\
\text { professional matters in shared spaces such as garden, balcony or living room }\end{array}$ \\
\hline Lack of backups & Lack of regular data backups, in at least 2 different devices, in different locations \\
\hline Targets always home & Easier to target cybersecurity and physical attacks to people confined in their home \\
\hline Cameras and microphones & $\begin{array}{l}\text { With people constantly online, cameras and microphones are on, most of the time. } \\
\text { They can still be on even when not needed and attackers can take advantage of this }\end{array}$ \\
\hline No/improper access control & Lack of access control measures for all the people using shared devices and accounts \\
\hline $\begin{array}{r}\text { Fake deliveries and access } \\
\text { to the house }\end{array}$ & $\begin{array}{l}\text { With people in insolation and constantly online buying food and other products, fake } \\
\text { deliveries can easily deceive people and attackers can rob/harm people }\end{array}$ \\
\hline Fear and discrimination & People infected may be discriminated/mistreated and targeted online \\
\hline Masks & $\begin{array}{l}\text { With masks it is even easier to impersonate someone and enter a health institution, } \\
\text { it is difficult to quickly ascertain someone's identity }\end{array}$ \\
\hline Gloves & Cannot use biometric fingerprint authentication to access health spaces/systems \\
\hline Break work policies/rules & $\begin{array}{l}\text { In mixed contexts people should be aware of the same regulations and policies of } \\
\text { their organization to always apply, when working from home }\end{array}$ \\
\hline ess use & $\begin{array}{l}\text { Home systems/infrastructures may not be regularly updated and their continued use } \\
\text { on periods such as this, can make them less resilient }\end{array}$ \\
\hline
\end{tabular}

\section{DISCUSSION AND RECOMMENDATIONS}

This work identifies and discusses very relevant cybersecurity issues in times of pandemic, and strives to make the research community, and the public in general, aware, so that adequate means are developed to face them. Due to space constraints, the authors will highlight and discuss only some of the identified issues.

In terms of review results, works mostly focus on direct challenges and much less on indirect. In fact, maybe due to the short time that has elapsed since the beginning of the pandemic, is still early for researchers and people to think, and even realize, the wider range of consequences that COVID-19 has brought to our lives. For one of the most focused direct cybersecurity challenges in the literature (i.e., contact tracing), many more issues need to be discussed and addressed. In fact, the balance between sharing and the privacy of personal data is really crucial but very hard to achieve, since the need for a high degree of anonymity makes it much harder to control or audit, and if we cannot trust data integrity and quality, it will not be useful for the proposed goals. Data integrity can only be achieved by letting some degree of privacy slip away, ideally to a trusted entity. It is advised that apps should not be rolled out without pilot studies or risk assessments being published (Nature, 2020), yet this has not been the case, as various countries have already released this kind of technology without proper transparency measures (Ekong, 2020). Means are needed to wind back to a world with greater privacies, after the crisis declines (Pesce, 2020) and to provide transparency and continuous risk assessment, including, the certification of the used technology, the provision of links with proper regulatory and cybersecurity authorities, together with external auditing to keep track of what is being done and how. 
In terms of data sharing, the authors will highlight two issues. Now that some countries are starting to deconfine, there have been some measures to monitor workers' and students' body temperature. These, or similar measures, can be invasive to the privacy and physical space of the individuals, and may not even have a legal basis, so need to be properly addressed and discussed. Another issue relates to a wider subject, also important in non-pandemic times, but that may negatively exacerbate in pandemic times, which is research integrity. Many governments and health authorities may try to base their decisions on epidemiological and research results, without proper verification/certification by other research groups or entities (although time is of essence). Such important life/death decisions must be taken on the most updated and corrected data results.

One final direct issue, with no solution at sight but very relevant, is the great increase of social engineering attacks and fake campaigns associated with COVID-19 (WHO, 2020). Fakenews, fear, isolation and lack of awareness, can turn the confined population into a highly vulnerable target to those attacks (INTERPOL, 2020). This issue needs addressing as no proper solutions exist, and this is only bound to exponentiate.

On the indirect cybersecurity issues related to COVID-19, these are very relevant to address, since other fatalities have and will happen as a consequence of the pandemic, which could probably have been avoided. The stress on remote support and consultation (e.g., telemedicine) for chronical, mental diseases or other conditions, such as pregnancy, is now a reality, but no proper cybersecurity standards are available to protect these connections. The subject has been studied for several years but now that is really needed, pressure is put on home, health and professional's infrastructures, without proper testing and monitoring, and without proper study on its impact to patients' privacy, physical integrity and safety. For cybersecurity, the most important asset are people, so the connection between people's health, the pandemic and cybersecurity, is close indeed.

One more word in relation to children and adolescents and how they are also affected by cybersecurity challenges. They are, together with elderly people, more prone to attacks and persuasion, so privacy and security measures in times of pandemic (but not only) need to adapt to various types of populations and their specific characteristics and needs. Current infrastructures are not adequate for kids to perform secure and safe homeschooling, sports, music and communication activities online, with teachers or friends and family. Out of the box and innovative solutions are required. Maybe transforming peoples' identities into high-fidelity digital humans could prevent, at least, some of the privacy and physical issues that arise from online conference calls.

Finally, many new behaviours that have been introduced quickly to face emergency states may not have been tested accordingly and may also generate undesired consequences. Examples include material such as masks, gloves and even full protection suits in areas with infected patients. These are certainly very important equipment to be used by health professionals and other types of workers. In some countries, regulations are imposed for the public to wear masks in public confined places. However, all these facilitate identity hiding and impersonation, which in healthcare related situations (but not only) can be life threatening. Maybe this is not yet the time to deal with these specific problems as attending to patients is certainly more important, still, attackers and fraudsters are always alert and take advantage of these holes in the system.

Cybersecurity as well as any other recommendations, measures, regulations or tools, can be used to perform the required goals, but also be subverted and used to perform less appropriate actions. Researchers, developers and everyone in general, need to be more aware of this to better balance these dual risks and consequences, especially crucial in life threatening situations.

Limitations: the sample size found in the literature was small probably due to the short period of time analysed and the time needed to publish those works; also, the review was performed by only one researcher. The identified complementary issues rely mostly on authors' expertise and a few on other sources such as news, technical magazines and cybersecurity sites. However, those data are scattered around, and this study helps to provide a unique/comprehensive way to make them available for future research and improvement. Due to space constraints, it was not possible to lengthily discuss recommendations to mitigate all presented challenges.

\section{CONCLUSION}

None of the identified cybersecurity challenges is new, however, the current pandemic has stressed the need for a more comprehensive analysis and adequate response to both direct and indirect issues related to COVID-19, very much intertwined into our daily lives. This work discusses those cybersecurity issues that require more resilient solutions from multidisciplinary sources that range from physical, social, ethical, behavioural, psychological to regulatory and technical knowledge; and stresses the necessity to take back our fundamental right for privacy after this unusual situation ends, as the impact of COVID-19 in cybersecurity and in the privacy and physical integrity of individuals will have to be handled, much after the pandemic subsides. 


\section{ACKNOWLEDGEMENT}

This work has been funded by TagUBig - Taming Your Big Data (IF/00693/2015) from Researcher FCT Program funded by National Funds through FCT.

\section{REFERENCES}

Abeler, J., Bäcker, M., Buermeyer, U. and Zillessen, H., 2020. COVID-19 Contact Tracing and Data Protection Can Go Together. In JMIR Mhealth Uhealth, 8(4):e19359.

COVID-19 Cyberthreats, 2020. INTERPOL. Available at: https://www.interpol.int/en/Crimes/Cybercrime/COVID-19cyberthreats. Accessed in May 2020.

Ekong, I., Chukwu, E. and Chukwu, M., 2020. COVID-19 Mobile Positioning Data Contact Tracing and Patient Privacy Regulations: Exploratory Search of Global Response Strategies and the Use of Digital Tools in Nigeria. In JMIR Mhealth Uhealth, 8(4): 19139.

Finch. J, 2020. Legal aspects of COVID-19 pandemic management for community nurses. In British Journal of Community Nursing, 25(4): 196-199.

Ienca, M. and Vayena, E., 2020. On the responsible use of digital data to tackle the COVID-19 pandemic. In Nat Med, 26(4):463-464.

Lenert, L. and McSwain, BY., 2020. Balancing Health Privacy, Health Information Exchange and Research in the Context of the COVID-19 Pandemic [published online ahead of print, 2020 Mar 31]. In J Am Med Inform Assoc.

Jawaid, A., 2020. Protecting older adults during social distancing. In Science, 368(6487):145.

Kavoor, A.R., Chakravarthy, K., and John, T., 2020. Remote consultations in the era of COVID-19 pandemic: Preliminary experience in a regional Australian public acute mental health care setting. In Asian Journal of Psychiatry, 51

Kummitha, RKR, 2020. Smart technologies for fighting pandemics: The techno- and human- driven approaches in controlling the virus transmission [published online ahead of print, 2020 Apr 20]. In Gov Inf Q,101481.

Mirco, N. et al, 2020. Give more data, awareness and control to individual citizens, and they will help COVID-19 containment. In Transactions on Data Privacy, 13(1): 61-66.

Nature, 2020. COVID-19 digital apps need due diligence. In The international journal of science. Springer Nature, Vol. 580, 563.

Naudé, W., 2020. Artificial intelligence vs COVID-19: limitations, constraints and pitfalls [published online ahead of print, 2020 Apr 28]. In AI Soc, 1-5.

Now, You Can Consult a Doctor on WhatsApp: Govt Issues Telemedicine Guidelines, 2020. india.com. Available at: https://www.india.com/news/india/now-you-can-consult-a-doctor-on-whatsapp-govt-issues-telemedicine-guidelines3981377/. Accessed in May 2020.

Park, S. and Choi GJ, Ko. H, 2020. Information Technology-Based Tracing Strategy in Response to COVID-19 in South Korea-Privacy Controversies [published online ahead of print, 2020 Apr 23]. In JAMA.

Pesce, M., 2020. Privacy in the time of Covid-19. In IEEE Spectrum, vol. 57, no. 5, pp. 23-23.

Rajan, D., Koch, K., Rohrer, K., Bajnoczki, C., Socha, A., Maike, V., Marjolaine, N., Valéry, R. and Justin, K., 2020. Governance of the Covid-19 response: a call for more inclusive and transparent decision-making. In British Medical Journal Global Health, 5, 2655.

Rajkumar, P., 2020. COVID-19 and mental health: A review of the existing literature. In Asian Journal of Psychiatry, 52. WHO reports fivefold increase in cyber-attacks, urges vigilance. 2020. WHO news release. Available at: https://www.who.int/news-room/detail/23-04-2020-who-reports-fivefold-increase-in-cyber-attacks-urges-vigilance Accessed in May 2020.

Yao H, Chen JH, Xu YF., 2020. Patients with mental health disorders in the COVID-19 epidemic. In Lancet Psychiatry, 7(4): e21.

Yasaka, TM., Lehrich, BM. and Sahyouni, R., 2020. Peer-to-Peer Contact Tracing: Development of a Privacy-Preserving Smartphone App. In JMIR Mhealth Uhealth, 8(4):e18936. 